\title{
Modelling and Analysis of Multi-period Distribution-Allocation Problem in a Two-Stage Supply Chain
}

\author{
A. Nimmu Mary Ivan
}

\begin{abstract}
A supply chain has a network structure and all the production-distribution decisions involve several variables and constraints which vary both quantitatively and qualitatively.

Mostly, production and distribution functions are managed independently, with little or no coordination which results in huge inventory holding costs and backorder costs. Hence, supply chains are exploring strategies to reduce the inefficiencies and the redundancies along the manufacturing/ distribution channel, which can eventually lead to a closer coordination between the various supply chain partners. One such strategy is to effectively allocate the downstream entities to the upstream entities.
\end{abstract}

Hence, this paper considers a multi-period distributionallocation problem(MPDAP) subjected to backorder and inventory constraints. It's mathematical formulation is difficult to solve due to the presence of fixed costs which causes nonlinearities in the objective function. The MPDAP is known to be Non-deterministic Polynomial-time hard problem. The complexity of the problem increases as and when more constraints are imposed into the model and problem size increases. In this work, an MPDAP is solved using an Ant colony optimization based heuristic to get a near-optimal solution. The proposed heuristic has been evaluated for the solution robustness by comparing it with that obtained using LINGO solver. A range of problem instances were considered in which suppliers, customers and time-periods were varied from 2-8. The percentage deviation of ACO cost from optimal solution obtained from LINGO was around $2 \%$.

Keywords--- Supply Chain, Multi-period Distribution Allocation Problem, Ant Colony Optimization, LINGO Solver

\section{INTRODUCTION}

I NDUSTRIAL logistics as a business term simply refers to the overall management of the way resources are obtained, stored and moved to the locations where they are required, while in reality it is a wide-reaching concept which incorporates various forms of supporting activities.

For industries with scattered production facilities and customers, the allocation of resources becomes challenging. This work becomes more tricky in the current scenario of

A. Nimmu Mary Ivan, Department of Mechanical Engineering, Muthoot Institute of Technology and Science, Varikoli, Kochi, Kerala, India.

DOI: 10.9756/BIJIEMS.8110 increased logistic costs like transportaion and storage, due to steep rise in the fuel costs. The success stories of many businesses can be directly to their Logistics and Supply Chain management techniques.

Many practical distribution problems in an industry sector can be modelled as a multi-period fixed charge distribution model. A multi-period model has several applications such as delivery of automobile accessories from the industrial producers to the final automobile assembling centres or the supply of consumer durables to the dealers from the industrial producers [3],etc.

A supply chain with a network structure involves many quantitative and qualitative variables and constraints for production-distribution decisions.

A distribution-allocation problem in a supply chain can be modeled as a multi-period distribution-allocation problem (MPDAP) subjected to backorder and inventory constraints. In a MPDAP, the transportation cost component involves the following costs:

- Variable cost, which depends on the shipment quantity and

- Fixed cost for a transportation route, which is independent of the shipment quantity.

The objective of this MPDAP is to determine the shipment quantity, backorder and inventory at each period so that the total cost incurred during the period towards transportation, backorder and inventory is minimized. The mathematical formulation of an MPDAP is difficult to solve due to the presence of fixed costs which causes nonlinearities in the objective function. The MPDAP is known to be Nondeterministic Polynomial-time hard problem. The complexity of the problem increases as and when more constraints are imposed into the model and problem size increases. In this work, an MPDAP is solved using an Ant colony optimization based heuristic to get a near-optimal solution.

This work is aligned with the model proposed by Jawahar et al.[3] and proposes an Ant Colony Optimization (ACO) based heuristic for solving the model. Also robustness of the proposed algorithm was checked by solving the model using LINGO.

In this paper, a fixed-charge transportation problem (FCTP) in a multi-period distribution-allocation problem is considered. 


\section{LITERATURE REVIEW}

Due to extensive practical and theoretical scope of multiperiod distribution problems, several works has been conducted related to this topic. The fixed-charge problem is a problem of practical interest to both business and industry sector. The FCTP was first introduced in Operations Research, as a special case of the fixed cost linear programming problem.

Fixed-charge transportation problems are mostly analyzed in terms of their solution methodology. Commonly approached solution procedures for an FCTP was based on exact algorithms and approximation algorithms. Murty[31] proposes a methodology for solving a fixed charge transportation problem by concentrating the search among the adjacent extreme points of the transportation problem. Gray[21] develops a solution methodology, namely search among the extreme points at vertices near the minimum fixed cost. Later a branch-and-bound procedure for solving an FCTP in a single-stage supply chain was proposed. It gives way to the Lagrangean relaxation method to generate penalties for choosing branching variables and fathoming nodes in the branch-and-bound technique.

All these literatures concluded that the time is an important factor in NP-hard problems. The review of the literature point outs that, since the FCTP is NP-hard, the computational time to obtain a solution increases in a polynomial fashion. As the size of the problem increases, the computational time of exact algorithm becomes difficult and long. This motivates the researchers to develop approximation methods. Adlakha and Kowalski [2] put forward a heuristic algorithm for solving small fixed charge transportation problems. However, it point outs that the proposed method is more time-consuming than the algorithms for solving a regular transportation problem. Raj and Rajendran[33] consider a single-stage supply chain and is solved using simple heuristic algorithms and their performances are compared with the existing best method by making use of benchmark problem instances.

Later, meta-heuristic based algorithms were proposed for solving fixed cost transportation problem. Genetic Algorithm based meta-heuristic proved to be a better solution technique than a heuristic method for solving an FCTP in a single-stage supply chain. Solution methodology based on Tabu-search meta-heuristic was also accepted for solving an FCTP in a single-stage supply chain. Raj and Rajendran [34] in his paper propose genetic algorithms to solve a two-stage transportation problem with two different scenarios).

In a supply chain, a production planning and distribution planning are interdependent problems. As these problems are mutually related, they should be dealt simultaneously in an integrated manner [26]. Haq et.al[22] formulates a model for a distribution-allocation problem with backorder in fertilizer industry. Later Chandra and Fisher[13]extended the model by considering vehicle-routing decisions. Barborsogluand Ozgur [7] consider a just-in-time environment and solve a problem with demand pattern with no backorder using Lagrangean relaxation method. Dogan and Geotschalckx [17] consider a deterministic demand pattern and apply a Benders decomposition method considering a case study in packaging industry. Abelmaguid and Dessouky [1] develop a solution approach based on genetic algorithm for solving a productiondistribution problem with a backorder and a penalty function. Chun and Zhang (40) solve a production-distribution problem using a genetic algorithm.

A notable research gap in the literature is that most of the work has not included fixed charge for transportation routes, in the integration of inventory and transportation costs.

When we go through the literature review in solution methodology, Ant Colony Optimization (ACO) is a metaheuristic approach proposed by Colorni et al.[14]. Later the approach is improved by Dorigo et al.' [18] by developing the Ant Colony System. The earlier application of ACO is to solve the well-known NP-Hard Traveling Salesman Problem[14], [15],[11] have provided a detailed description of the basics of the ACO algorithm, it applications, and its successful variants. Several studies have applied ACO to solve different discrete and continuous optimization problems, such as vehicle routing, quadratic assignment problems and graph coloring [18]. report more than 30 problems where ACO-based algorithms have been used successfully. Most of these problems can be represented in the form of a network or graph. With the successful implementation of the ACO approach, the significance of the approach for solving these problems has been recognized by researchers and practitioners.

In summary, the review of the multi-period distributionallocation problem and fixed-charge transportation problem reveals the following:

- Most of the models consider integrating inventory and transportation costs.

- Excess in availability of the product in any period is held as inventory at the supplier's end and is used for the subsequent periods. Inventory at the demand points has not been given due consideration.

- Most of the research has not included the fixed charge associated with a transportation route.

- Most of the work apply Genetic Algorithm based heuristic for solving the problem while only limited work is done using other meta-heuristic such as Ant Colony Optimization (ACO) algorithm, Tabu search etc.

- There exists a shortage of literature on Multi-period Multi-stage Distribution-allocation problem in a Supply Chain. In the literature there are no work studying multi-period distribution-allocation problem in a two-stage supply chain considering fixed cost for transportation route.

Hence in this paper, a multi-period distribution allocation problem in a two-stage supply chain with fixed cost for transportation route is considered. An Ant Colony Optimization (ACO) based heuristic is proposed to solve the MPDAP model. 


\section{PROBLEM ENVIRONMENT}

\subsection{Problem Description}

Consider an MPDAP in which there are $p$ plants (suppliers or warehouses), $q$ number of distribution centres (warehouses or retailers), and $r$ customers (retailers or end users). Figure: 1 shows the pictorial representation of the two-stage supply chain fixed charge distribution problem under consideration.

\subsubsection{Mathematical Model}

Assumptions used are the following:

1) Single product demand for multiple periods is considered.

2) The number of suppliers and their capacities, customers and their demand are known.

3) The number of distributors is known and their capacity is assumed to be infinite

4) A Customer can be supplied with products from more than one Distributors respectively

5) A distributor can be supplied with products from more than one Suppliers respectively

6) Transportation damages or losses are not considered.

7) Lead time is assumed to be zero

In each period $P_{i}^{t}$ is taken as the units produced by each supplier and $D_{k}^{t}$ as the units demanded by each customer. Each of the suppliers 'i' is free to distribute their product to any of the customer k. During these shipments, a variable cost which is directly proportional to the quantity to be shipped is included. This variable cost is called unit transportation cost denoted by $C_{i k}$. In addition to this cost component, a fixed cost component is also included in each shipment. It is denoted by $\mathrm{FC}_{\mathrm{ik}}$.

At any time period $t$, the total cumulative production of the suppliers and the total cumulative demand of the customers may or may not be equal (could be higher or lesser). The excess or shortage of production is carried over to the subsequent period $t+1$. The excess of production is addressed here as inventory, while the production shortage (excess demand) of the period is addressed as backorder. For the period $t+1$, inventory can be considered as an additional supply and the backorder as the additional demand.

At a period, when the inventory is at the supplier's side, per unit inventory holding cost is denoted as $S H_{i}$, and at the customers side it is $\mathrm{CH}_{\mathrm{k}}$. As the proposed model considers short planning periods (days/weeks/months), the costs associated with transportation (i.e. $C_{i k}$ and FCij), inventory (i.e. $\mathrm{SH}_{i}$ and $\mathrm{CH}_{k}$ ) and backorder (i.e. $\mathrm{BCj}$ ) are independent of period t.The beginning period's inventory and backorder (i.e. $S I_{i}^{t}, C I_{k}^{t}$, and $B L_{j}^{t}$ ) are known quantities. The objective criterion of the model is the minimization of the total costs which is the sum of the costs of transportation, the costs of holding inventory and the costs of penalty for the backorder supply.

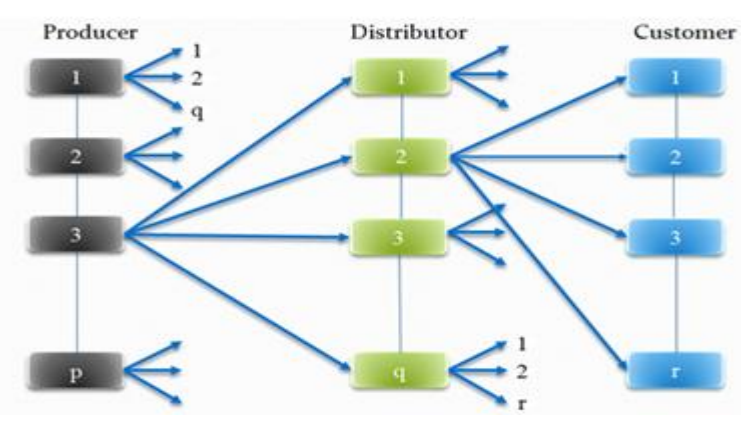

Fig. 1

Fig. 1: Operational elements of multi-period two stage fixed charge distribution problem during the period $t$ where ' $p$ ' suppliers can supply to any of the ' $q$ ' distributors which in turn can supply to any of the customers ' $r$ '

\subsection{Mathematical Model}

\section{Notation:}

The indices used in the model are as follows:

$i \quad$ Supplier index $(1,2 \ldots \mathrm{p})$

$j \quad$ Distributor index $(1,2 \ldots \mathrm{q})$

$k \quad$ Customer index $(1,2 \ldots \mathrm{r})$

$t \quad$ Time index $(1,2 \ldots \mathrm{T})$

Parameters:

$S_{i}^{p}$ Supplier's production capacity

$D_{k}^{r}$ Customer demand

$U_{i k} \quad$ Unit Transportation cost

$F C_{i k}$ Fixed Transportation cost

$\mathrm{CH}_{k}$ Customer's inventory holding cost per unit time

$\mathrm{SH}_{i} \quad$ Supplier's inventory holding cost per unit time

$B C_{k} \quad$ Customer backorder penalty cost per unit time

$X_{i j}^{t} \quad$ Optimal size of the shipments

$C I_{k}^{t}$ Customer's beginning inventory

$S I_{i}^{t} \quad$ Supplier's beginning inventory

Decision Variables

$$
\delta_{i j}^{t}\left\{\begin{array}{l}
1 \ldots \text { when } \ldots . X_{i j}^{t}>1 \\
0 \ldots \text { otherwise }
\end{array}\right.
$$

Binary variable between supplier and distributor

$$
\delta_{j k}^{t}\left\{\begin{array}{l}
1 \ldots \text { when } \ldots X_{j k}^{t}>1 \\
0 \ldots \text { otherwise }
\end{array}\right.
$$

Binary variable between customer and distributor 


\subsection{Objective Function}

In this work, the problem environment comprises of $p$ suppliers to distribute a product to $q$ distributors and then to $r$ customers in $T$ planning periods. The model integrates the production, transportation, backorder and inventory decisions in a single-stage supply chain. The mathematical model of the MPDAP considering a fixed cost for transportation route is formulated as a Pure Integer Non-Linear Programming (PINLP) problem as given below.

The objective function of the model can be stated as follows.

Minimize $Z$

$$
\begin{aligned}
& Z=\sum_{t=1}^{T} \sum_{i=1}^{p} \sum_{j=1}^{q}\left(C_{i j}^{t} X_{i j}+F_{i j} \delta_{i j}\right)+\sum_{i=1}^{T} \sum_{j=1}^{q} \sum_{k=1}^{r}\left(C_{j k}^{t} X_{j k}+F_{j k} \delta_{j k}\right)+ \\
& \sum_{t=1}^{T-1} \sum_{i=1}^{p}\left(S H_{i} * S I_{i}^{t}\right)+\sum_{t=1}^{T-1} \sum_{k=1}^{r}\left(C H_{k} * C I_{k}^{t}\right)+\sum_{t=1}^{T-1} \sum_{k=1}^{r}\left(B C_{k} * B L_{k}^{t}\right)
\end{aligned}
$$

Subject to:

$$
\begin{gathered}
\sum_{t=1}^{T} \sum_{j=1}^{q} X_{i j}^{t} \leq S_{i}^{t}\left(\forall_{i,} i=1,2, \ldots, p\right) \\
\sum_{t=1}^{T} \sum_{j=1}^{q} X_{j k}^{t}=D_{k}^{t}\left(\forall_{j,} k=1,2, \ldots, r\right) \\
D_{k}^{t}+B L_{k}^{t-1}-C I_{k}^{t-1}=\sum_{j=1}^{q} \sum_{i=1}^{r} X_{j k}^{t}+B L_{k}^{t}-C I_{k}^{t} \\
S_{i}^{t}+S I_{i}^{t-1}=\sum_{i=1}^{p} \sum_{j=1}^{q} X_{i j}^{t}+S I_{i}^{t} \\
X_{i j}^{t} \geq 0 \\
X_{j k}^{t} \geq 0 \\
\delta_{i j}^{t}\left\{\begin{array}{l}
1 \ldots \text { when } \ldots . . X_{i j}^{t}>1 \\
0 \ldots \text { otherwise }
\end{array}\right. \\
\delta_{j k}^{t}\left\{\begin{array}{l}
1 \ldots \text { when ...X } X_{j k}^{t}>1 \\
0 \ldots \text { otherwise }
\end{array}\right.
\end{gathered}
$$

The objective of the mathematical model is to minimize the sum of the total costs associated with production, transportation, inventory at supplier's and customer's end and backorder. The first term of the objective function provides the total cost of transportation between suppliers and distributors for the entire period $T$ and the second term provides the total cost of transportation between distributors and customers for the entire period $T$. The third term addresses the total cost of holding inventory at supplier's locations for the entire period $T$. The fourth and the fifth terms indicate respectively the total cost holding inventory for the entire period $T$ and the total cost of backorder penalty for the entire period $T$. The model is subjected to the following constraints:

According to constraints (1) and (2) the material should be balanced at the customer's side between any two successive time intervals. According to constraints (3) and (4) the material should be balanced at the supplier's side between any two successive time intervals. Either inventory or backorder is present in any of the side of these equations. Constraints (5) and (6) return a value for the binary variable when there is shipment. Constraints (7) and (8) ensure that the decision variables are having integer values and are non-negative.

\section{Solution Methodology}

The above formulated MPDAP model is difficult to solve due to the presence of fixed costs, causing non-linearity in the objective function. In this work, the MPDAP is solved using an Ant Colony Optimization (ACO) based heuristic to obtain a near-optimal solution. The proposed heuristic comprises of the following four stages

- Initialization

- Node Transition

- Pheromone updating and

- Termination.

ACO algorithm, a biological-inspired solution methodology for FCTP is a meta-heuristic technique. It is based on the behavior of real ants in natural world, in search of food using the shortest path.At first, the ants wander randomly. The ants communicate using a chemical substance called pheromone. When an ant finds a source of food, it walks back to the colony leaving "markers" (pheromones) that show the path has food. When other ants come across the markers, they are likely to follow the path with a certain probability. If they do, they then populate the path with their own markers as they bring the food back. As more ants find the path, it gets stronger until there are a couple streams of ants travelling to various food sources near the colony. Because the ants drop pheromones every time they bring food, shorter paths are more likely to be stronger, hence optimizing the "solution." In the meantime, some ants are still randomly scouting for closer food sources, looking for any other shorter path. Once the food source is depleted, the route is no longer populated with pheromones and slowly decays.

Ant Colony Optimization Algorithm (ACO) possesses the enhanced abilities such as memory of past actions and knowledge about the distance to other locations in the search process.

\subsection{Proposed ACO-based Heuristic}

The steps involved in the ACO-based heuristic are described in the following subsections.

\subsubsection{Determination of Various Costs at Different Periods}

The distribution-allocation at different periods involving inventory and backorder costs, variable and fixed cost is determined according to the following conditions.

Calculation of variable transportation cost:

Taking demand period as $t_{d}$ and supply period as $t_{s}$,

Case 1: $t_{d}=t_{s}$

When demand of a period is met in the same period itself, variable cost remains unchanged. 
Case 2: $t_{d}>t_{s}$

When demand of a period is met from the inventory of the previous period, existing variable cost is re-calculated by adding supplier's or customer's inventory holding cost. Minimum of this cost taken for adding to the total cost.

$$
\begin{aligned}
& \text { Variable cost }=U_{i j}+H S_{i} \times\left(\mathrm{t}_{\mathrm{d}}-\mathrm{t}_{\mathrm{s}}\right) \\
& \text { Variable cost }=U_{i j}+H S_{i} \times\left(\mathrm{t}_{\mathrm{d}}-\mathrm{t}_{\mathrm{s}}\right)
\end{aligned}
$$

Case 3: $\mathrm{td}<\mathrm{ts}$

When demand of the period td is met as backorder, from the period ts, the variable cost is recalculated by adding backorder costs also.

$$
\text { Variable cost }=U_{i j}+B C_{j} *(\text { td-ts })
$$

\subsubsection{Calculation of Fixed Transportation Cost}

The calculation of fixed transportation cost depends on the period in which the shipment is done.

Case 1: $\mathrm{td}=\mathrm{ts}$

Transportation is done in the same period as the demand. Thus, fixed transportation cost remains same.

Case 2: $\mathrm{td}>\mathrm{ts}$

The demand is met from the previous period's inventory of either supplier or customer. When there is supplier's inventory, there exists no shipment and thus the quantity has to be shipped in this period and incurs a fixed cost in the transportation. Similarly, if the inventory is stored at the customer location in the previous period, no fixed cost is incurred in the period.

Case 3: $\operatorname{td}<\mathrm{ts}$

The demand is met as backorder for the coming periods. For a period, if the shipment of backorder is taking place in the period ts, then the fixed cost of this period is zero, on the contrary; if the shipment is taking place in this period, there exists a fixed cost.

\subsection{Implementation of ACO-based Heuristic for MPDAP}

In a single stage supply chain, using Monte-Carlo simulation procedure, a matrix is generated in which all the customers, suppliers and time-period are specified. An ant starts to move from the chosen customer. The ant selects that supplier in which the cumulative probability value is greater than the random number.

Each ant starts from the first customer and moves to the position of the supplier $\mathrm{s}$, in time period $\mathrm{t}$, as determined by the random number generated and transition probability. The customer demand and the supplier capacity are considered and the minimum of this is allotted as the shipment quantity. This procedure is continued till the demand of the first customer is satisfied or capacity constraint of supplier is met.

The ant selects the next customer and the same procedure is continued till an allotment pattern satisfying the demand and capacity constraints is satisfied. In the edges where an allocation is done, the ant deposits an additional pheromone as compared to other edges where there is no allocation which increases its visibility. Hence for next ant, the probability of selecting that node is more.

The total cost is computed as the objective function value for the complete allocation of the artificial ant. The ACObased heuristic constructs the complete allocation for the first ant prior to the second ant starting its allocation. This continues until a predetermined colonies of ants $\mathrm{m}$, each construct a feasible allocation.

\subsection{Parameter Setting}

The correct choice of parameters and operators decides the effectiveness of heuristic algorithms. Among several experimental design techniques, the Taguchi method has been successfully applied for a systematic approach for optimization(Phadke, 1989) and (Taguchi, 1986).

The Taguchi method involves reducing the variation in a process through robust design of experiments. The overall objective of the method is to produce high quality product at low cost to the manufacturer. The experimental design proposed by Taguchi involves using orthogonal arrays to organize the parameters affecting the process and the levels at which they should be varies. Instead of having to test all possible combinations like the factorial design, the Taguchi method tests pairs of combinations. The Taguchi method is best used when there are an intermediate number of variables ( 3 to 50), few interactions between variables, and when only a few variables contribute significantly.

\subsubsection{Determining Parameter Design Orthogonal Array}

Experimental design usually involves attempting to optimize process which can involve several factors.

The parameters used in ACO-based heuristic and their levels are:

$\alpha \quad$ the relative importance of trail, $\alpha \geq 0$

$(0.2,0.4,0.6,0.9 ., 0.99)$

$\beta \quad$ the relative importance of visibility, $\beta \geq 0$

$(0.2,0.4,0.6,0.9,0.99)$

$\rho$ A coefficient such that (1- $\rho$ ) represents the evaporation rate, $0 \leq \rho<1$

$(0.2,0.4,0.6,0.9,0.99)$

$\mathrm{n}$ number of ants

$(5,10,20,50,100)$

Q a constant related to the quantity of trail laid by ants

$(5,10,100,1000,10000)$

Here, in our experiment we are having 5 set of parameters with 5 levels so it's possible to take L25 array. Parameter setting using Taguchi method was done in Minitab.

Thus the best combinations of parameter values from Taguchi method are as follows:

$$
\begin{aligned}
& \alpha=0.90, \beta=0.90, \rho=0.99 \\
& n=50, Q=10
\end{aligned}
$$




\subsection{Validation of ACO-based Heuristic}

According to the Jawahar et.al[4], an optimal solution cannot be obtained using the constraints imposed in the objective function, as there exists a non-linearity function due to the presence of fixed-cost. So the linear distribution model is made by relaxing the integrality restrictions of the problem with an equivalent variable transportation cost.

The problem can now be solved in LINGO solver and an optimal cost with a distribution schedule can be determined. In order to validate the solution obtained using ACO-based heuristic, a comparison is made between the solution obtained from proposed heuristic and that of LINGO. Further a set of problem instances are randomly generated varying the number of suppliers, the number of customers and the time-periods. All these variables are varied from two to eight.

\section{NUMERICAL ILLUSTRATION}

STEP 1: The input data for a MPDAP in a two-stage supply chain is provided in Tables $1-11$

\section{STEP 2: Applying State Transition Rule}

In this step, the probability matrices are calculated between each supplier node, distributor node and customer node. Initially, at each node a pheromone quantity of 0.5 units is assumed.

Table 1: Supplier Data

\begin{tabular}{|c|c|c|}
\hline \multicolumn{3}{|c|}{ SUPPLIER CAPACITY } \\
\hline & Supplier l & Supplier 2 \\
\hline TP1 & 70 & 40 \\
\hline TP2 & 50 & 30 \\
\hline Supplier holding cost & 5 & 12 \\
\hline Supplier inventory & 10 & 0 \\
\hline
\end{tabular}

Table 2: Customer Data

\begin{tabular}{|l|l|l|}
\hline \multicolumn{3}{|c|}{ CUSTOMER DEMAND } \\
\hline $\begin{array}{l}\text { TIME } \\
\text { PERIOD }\end{array}$ & Customer 1 & Customer 2 \\
\hline TP1 & 60 & 60 \\
\hline TP2 & 60 & 20 \\
\hline Holding cost & 15 & 10 \\
\hline $\begin{array}{l}\text { Back order } \\
\text { cost }\end{array}$ & 20 & 40 \\
\hline Back order & 0 & 20 \\
\hline $\begin{array}{l}\text { Customer } \\
\text { inventory }\end{array}$ & 0 & 30 \\
\hline
\end{tabular}

Table 3: Cost Data

\begin{tabular}{|l|l|l|l|l|l|}
\hline \multicolumn{2}{|c|}{} & \multicolumn{2}{|l|}{ Distributor 1 } & \multicolumn{2}{l|}{ Distributor 2 } \\
\cline { 3 - 6 } \multicolumn{2}{|c|}{} & Fixed cost & Unit cost & Fixec cost & Unit cost \\
\hline \multirow{2}{*}{$T P 1$} & Customer 1 & 90 & 30 & 65 & 40 \\
\cline { 2 - 6 } & Custurner 2 & 60 & 20 & 80 & 50 \\
\hline \multicolumn{2}{|c|}{} & Supplier 1 & Supplier 2 \\
\hline \multirow{2}{*}{$T 22$} & Distributor 1 & 525 & 40 & 600 & 10 \\
& Distributor 2 & 500 & 15 & 750 & 35 \\
\hline
\end{tabular}

The expected allocation cost between customers and distributors are calculated as given below:

Consider Distributor D1 and Customer C1. The expected allocation cost between $\mathrm{D} 1$ and $\mathrm{C} 1$ is calculated as:

Total cost $=f_{i j}+C_{i j} \times d_{i}=90+60 \times 30=1890$ monetary units.

(Where, $f_{i j}$ is the fixed cost between $C l$ and $D 1$ )

The calculated expected allocation cost between customers and distributors are given in Table 4.

Table 4: Expected Allocation Cost

\begin{tabular}{|c|c|c|c|c|}
\hline & \multicolumn{2}{|c|}{$P 1$} & \multicolumn{2}{c|}{$P 2$} \\
\hline & $D 1$ & $D 2$ & $D 1$ & $D 2$ \\
\hline$C 1$ & 1890 & 2465 & 1890 & 2465 \\
\hline$C 2$ & 1060 & 2580 & 1060 & 2580 \\
\hline$C 1$ & 1890 & 2465 & 1890 & 2465 \\
\hline$C 2$ & 460 & 1080 & 460 & 1080 \\
\hline
\end{tabular}

Table 5: Transition Probability Matrix

\begin{tabular}{|l|l|l|l|l|}
\hline & $D 1$ & $D 2$ & $D 1$ & $D 2$ \\
\hline$C 1$ & 0.2666 & 0.2334 & 0.2666 & 0.2334 \\
\hline$C 2$ & 0.3047 & 0.1953 & 0.3047 & .1953 \\
\hline$C 1$ & 0.2666 & 0.2334 & 0.2666 & 0.2334 \\
\hline$C 2$ & 0.3025 & 0.1975 & 0.3025 & .1975 \\
\hline
\end{tabular}

STEP 3: Ant Solution Generation

The cumulative probability matrix is determined and is given in Table 6.

Table 6: Cumulative Probability Matrix

\begin{tabular}{|l|l|l|l|l|}
\hline & \multicolumn{2}{|c|}{$P 1$} & \multicolumn{2}{c|}{$P 2$} \\
\hline & $D 1$ & $D 2$ & $D 1$ & $D 2$ \\
\hline$C 1$ & 0.5332 & 1 & .5332 & 1 \\
\hline$C 2$ & 0.6094 & 1 & .6094 & 1 \\
\hline$C 1$ & 0.5332 & 1 & .5332 & 1 \\
\hline$C 2$ & 0.5061 & 1 & .5061 & 1 \\
\hline
\end{tabular}

The allocation procedure between customers and distributors in a two-stage supply chain is carried out using a Monte-Carlo simulation method.

- For Time period TP1, Customer C1, a random number $\mathrm{R} 1$ is generated as 0.4354 . Using cumulative probability matrix, Distributor (D1) is selected. 60 units are allocated.

Demand of customer C1 is completely met. Now ant goes to customer C2

- $\quad$ For TP1, C1, R2 =0.8354

Distributor (D2) is selected.

50 units are allocated

Demand of customer C2 is completely met. Now ant goes to customer C1, in time period2.

- For TP2, C1, R3=0.7854

Distributor (D1) is selected.

60 units are allocated.

Demand of customer C1 is completely met. Now ant goes to customer C2, in time period2.

- $\quad$ For TP1, C1, R1=0.9136

Distributor (D1) is selected. 20 units are allocated. 6

The whole allocation procedure is depicted from Tables 1- 
Table 7: Allocation Procedure using Monte-Carlo Simulation Method

\begin{tabular}{|l|c|c|c|c|c|}
\hline & \multicolumn{2}{|c|}{$P 1$} & \multicolumn{2}{c|}{$P 2$} & demand \\
\hline & $\mathrm{D} 1$ & $\mathrm{D} 2$ & $\mathrm{D} 1$ & $\mathrm{D} 2$ & \\
\hline$C 1$ & 60 & & & & 0 \\
\hline$C 2$ & & 50 & & & 0 \\
\hline$C 1$ & & & & 60 & 0 \\
\hline$C 2$ & & & & 20 & 0 \\
\hline
\end{tabular}

Similarly, an initial pheromone matrix is generated between suppliers and distributors. An expected allocation cost is calculated and provided in Table 9.

Table 8: Distributor Demand Matrix

\begin{tabular}{|l|l|l|}
\hline & D1 & D2 \\
\hline P1 & 60 & 50 \\
\hline P2 & 0 & 80 \\
\hline
\end{tabular}

Table 9: Expected Allocation between Supplier and Distributor

\begin{tabular}{|l|l|l|l|l|l|}
\hline & \multicolumn{2}{|c|}{ P1 } & \multicolumn{2}{c|}{ P2 } & \\
\cline { 2 - 6 } & & S1 & S2 & S1 & S2 \\
\hline \multirow{2}{*}{ P1 } & D1 & 2925 & 1100 & 2925 & 1100 \\
\cline { 2 - 6 } & D2 & 500 & 1450 & 500 & 1450 \\
\hline \multirow{2}{*}{ P2 } & D1 & 2925 & 1100 & 2925 & 1100 \\
\cline { 2 - 6 } & D2 & 500 & 1450 & 500 & 1450 \\
\hline
\end{tabular}

The transition probability matrix is calculated and the cumulative probability is determined as provided in Table 10

Table 10: Cumulative Matrix

\begin{tabular}{|c|c|c|c|c|c|}
\hline \multirow{2}{*}{} & \multicolumn{2}{|c|}{ P1 } & \multicolumn{2}{|c|}{ P2 } & \\
\cline { 2 - 6 } & & S1 & S2 & S1 & S2 \\
\hline P1 & D1 & 0.3794 & 1 & 0.3794 & 1 \\
\cline { 2 - 6 } & D2 & 0.6324 & 1 & 0.6324 & 1 \\
\hline P2 & D1 & 0.3794 & 1 & 0.3794 & 1 \\
\cline { 2 - 6 } & D2 & 0.6324 & 1 & 0.6324 & 1 \\
\hline
\end{tabular}

A Monte-Carle Simulation method is adopted for the allocation of distributors to the suppliers. The allocation matrix between distributors and suppliers is given in Table 11

Table 11: Allocation Matrix between Distributors and Suppliers

\begin{tabular}{|c|c|c|c|c|}
\hline & (S1) & $($ (S2) & (S1) & (S2) \\
\hline (D1) & & & 10 & \\
\hline (D2) & 60 & 40 & & \\
\hline (D1) & & & & 20 \\
\hline (D2) & & & 50 & 10 \\
\hline
\end{tabular}

Total costs (in monetary units) $=$ Cost (Customer allocation + Distributor allocation $)=13715$

In the first iteration, based on the ant solution, the second ant solution is considered as the best ant solution.

- Total costs for First ant (in monetary units):13715

- Total costs for Second ant (in monetary units): 11875(Best Ant solution)

- Total costs for Third ant (in monetary units):11925

In the first iteration, the global best solution is same as the best ant solution.

Global Best solution $=$ Best Ant Solution $=11875$ (in monetary units).

Using the best ant solution, the pheromone level is revised and the procedure is continued for the pre-determined number of iterations.

\section{RESULTS AND DISCUSSION}

In this work, initially two problem instances from the literature(Jawahar et.al, 2011and Jawahar and Balaji, 2012) are solved by the proposed ACO-based heuristic and is validated using the LINGO software. The obtained results show the proficiency of the proposed algorithm in comparison with LINGO and the existing results in the literature.

Solution methodology adopted Simulated annealing algorithm

Objective function value 17860

(Jawahar et.al, 2011)

LINGO (Equivalent cost approach) 17347

Proposed ACO-based heuristic

17050

LINGO (Revising constraint)

16780

Solution methodology adopted GA and SAA based meta-heuristic

Objective function value

(Jawahar and Balaji, 2012)

LINGO (Equivalent cost approach) $\quad 27,170$

Proposed ACO-based heuristic

25,650

LINGO (Revising constraint)

Using the proposed ACO-based heuristic, many problem instances are generated in which the planning horizon is varied from 2 weeks to 8 weeks. Similarly, the number of suppliers and the number of customers are varied from 2 to 8. The computational time taken by the ACO-based heuristic increases as the planning horizon increases since the decision variables and the constraints are more. The solution obtained using ACO-based heuristic is compared for its robustness, with that obtained using LINGO solver. From the comparison, it is found that, LINGO generates optimal solutions while ACO heuristic can develop only a near-optimal solution. But there exists only a very small deviation between the solutions. In terms of computational time, LINGO solver takes more time to obtain solution. This computational time further increases as the planning horizon increases. Thus, for higher size problems, the proposed ACO-based heuristic provides near-optimal solution in less time in comparison with that of LINGO. In certain problem instance, the time taken is so high that, the solver is interrupted and a non-optimal solution is found using LINGO.

\section{CONCLUSION AND FUTURE SCOPE FOR THE WORK}

In this work, a mathematical model for the MPDAP associated with backorder and inventory is formulated. The transportation cost component in the MPDAP considered in this work involves variable cost and fixed cost. The objective of the model is to determine the size of the shipments, backorder and inventory at each period, so that the total cost 
incurred during the entire period towards transportation, backorder and inventory is minimized.

The above formulated MPDAP model is difficult to solve due to the presence of fixed costs, causing nonlinearities in the objective function and are known to be Nondeterministic Polynomial-time hard. Hence, to solve the formulated MPDAP, an ACO-based heuristic is developed to get a nearoptimal solution in this work.

The solution obtained using the proposed heuristic is validated by converting the MPDAP model into a Mixed Integer Programming (MIP) model and solving the MIP using LINGO-13 solver. A set of problem instances are randomly generated varying the number of suppliers, the number of customers and the time-periods from two to eight. The percentage deviation in the objective function value (total cost) obtained using ACO-based heuristic is more, ranging from $1.25 \%$ to $3.54 \%$ with that of LINGO solver.

As a future scope, the MPDAP model formulated in this work can be extended by including more supply chain partners.

\section{REFERENCE}

[1] Abdelmaguid T. F. and Dessouky M. M.. "A Genetic Algorithm approach to the integrated inventory-distribution problem. International Journal of Production Research”, Vol. 44 (21), Pp:4455-4464, 2006.

[2] Adlakha. V. \&Kowalski.K., "A simple heuristic for solving small fixedcharge transportation problems Omega. International Journal of Management Science”, 31, Pp:205-211, 2003.

[3] Balaji, A. N. and Jawahar, N., "A genetic algorithm based heuristic to the multi-period fixed charge distribution problem. Elsevier", Vol. 12(2), Pp:682-699, 2012.

[4] Balaji, A. N. and Jawahar, N., "A Simulated Annealing Algorithm for a two-stage fixed charge distribution problem of a Supply Chain. International Journal of Operational Research", Vol. 7(2), Pp:192-215, 2010.

[5] Ballou RH, "A continued comparison of several popular algorithms for vehicle routing and scheduling Business Logistics", 11(1), Pp:111-26, 1990

[6] Barbarosogluand.G and Ozgur.D. Hierarchical design of an integrated production and 2-echelon transportation system. European Journal of Operational Research, Vol. 118, Pp: 464- 484, 1999.

[7] Barbarosogluand.G and Ozgur.D, "Hierarchical design of an integrated production and 2-echelon transportation system. European Journal of Operational Research", Vol. 118, Pp:464- 484, 1999.

[8] Barros, L.L., Riley, M., and Brown, D., "A global view of industrial logistics. European Journal of Operational Research”, 129 (2), Pp:231234, 2001

[9] Bauer A, Bullnheimer B, Hartl RF, Strauss C., 1999.An ant colony optimization approach for the single machine tool tardiness problem. In: Proceedings of the 1999 Congress on Evolutionary Computation. pp. $1445-50$.

[10] Bauer A, Bullnheimer B, Hartl RF, Strauss C., "An ant colony optimization approach for the single machine tool tardiness problem. In: Proceedings of the 1999 Congress on Evolutionary Computation'. Pp:1445-50, 1999.

[11] Blum, C. (2005a). Ant colony optimization: Introduction and recent trends. Physics of Life Reviews, 2(4), Pp:353-373.

[12] Bullnheimer, B., Kotsis, G., \& Strauss, C.(1997).Parallelization strategies for the ant system. In P. Murli, P. Pardalos, \& G. Toraldovol, Kluwer Series of Applied Optimization.

[13] Chandra, P. and Fisher, M.L., "Coordination of production and transportation planning”. European Journal of Operational Research, 72, Pp:503-517, 1994.

[14] Colorni, A., Dorigo, M., Maniezzo, V., "Distributed optimization by ant colonies". In: Proceedings of ECAL91 - European Conference on Artificial Life, Paris, France, Pp:134-142, 1991.
[15] Colorni, M.Dorigo, V.Maniezzo, " The Ant System: Optimization by a colony of cooperating agents," IEEE Transactions on Systems, Man, and Cybernetics, Vol 26, Pp.1-13,1996

[16] Diaby M., "Successive linear approximation procedure for generalized fixed- charge transportation problems. Journal of Operational Research Society", 42. Pp. 991-1001, 1981.

[17] Dogan, K. and Goetschalckx, M.,"A primal decomposition method for the integrated design of multi-period production distribution systems. IIE Transactions", 31, Pp"1027-1036, 1999.

[18] Dorigo, M., Bonabeau, E., Theraulaz, G., Ant algorithms and stigmergy. Future Generation Computer Systems, 16, Pp:851-871, 2000.

[19] Fisher MA., 1994.Optimal solution of vehicle routing problems using minimum k-trees .Oper Res42:626-42.

[20] Flippo, C.D. and Finke, G., 2001. An integrated model for an industrial production-distribution problem.IIE Transactions, 33,705-715.

[21] Gray, P., "Exact solution of the fixed charge transportation problem. Operations Research", 19 (6), Pp:1529-1538, 1971.

[22] Haq, N., Vrat, P., and Kanda, A., "An integrated production-distribution model for manufacture of urea: a case .International Journal of Production Economics", 39, Pp:39-49, 1991

[23] Kaminsky .P andSimchi-Levi .D, "Production and transportation lot sizing in a two stage supply chain.IIE Transactions", Vol.35, Pp:10651075, 2003.

[24] KimJ. U. and KimY. D., "A Lagrangian relaxation approach to multi period inventory/distribution planning. Journal of the Operational Research Society", Vol.51, Pp:364-370, 2000.

[25] Kumar, R., Tiwari, M. K., \& Shankar, R. (2003).Scheduling of flexible manufacturing systems: An ant colony optimization approach. Proceedings of the I MECH E Part B Journal of Engineering Manufacture, 217(11), Pp:1443-1453.

[26] Lin S, Kernighan BW., 1973.An effective heuristic algorithm for the TSP. Oper Res 21, pp.498-516.

[27] McMullen P.R., "An ant colony optimization approach to addressing a JIT sequencing problem with multiple objectives. Artif.Intell .Eng”, 15, Pp:309-17, 2001.

[28] M. Dorigo, M. Birattari, T. Stützle, "Ant Colony Optimization Artificial Ants as a Computational Intelligence Technique", IEEE Computational Intelligence Magazine, 2006.

[29] M. Dorigo T. Stützle, "The Ant Colony Optimization Metaheuristic: Algorithms, Applications, and Advances", Handbook of Metaheuristics, 2002.

[30] M. Dorigo K. Socha, “An Introduction to Ant Colony Optimization”, T. F. Gonzalez, Approximation Algorithms and Metaheuristics, CRC Press, 2007.

[31] Murty, K.G., Solving the fixed charge problem by ranking the extreme points. Operations Research, Vol.16, Pp:268-279, 1968.

[32] Park. Y.B,. 2005. An integrated approach for production and distribution planning in planning in a Single-plant multi destination network," Journal of the Operational Research Society, Vol.59, Pp:90-104,.

[33] Raj K, Rajendran C., "Fast heuristic algorithms to solve a single-stage fixed- charge transportation problem. International Journal of Operational Research", 6, Pp:304-329, 2009.

[34] Rajendran et.al. "A genetic algorithm for solving the fixed-charge transportation model: Two-stage problem. Computers \& Operations Research", 39, Pp:2016-2032, 2012.

[35] RizkN., A. Martel, S. D., Amours. Synchronized productiontransportation supply chain management. International Journal of Production Research, Vol.43 (6), Pp:1205-1224, 2008.

[36] Ruiz .R.and Maroto .C, "A genetic algorithm for hybrid flow shops with sequence dependent setup times and machine eligibility. European Journal of Operational Research",169, Pp:781-800, 2006.

[37] SafaeiA.S.Moattar HusseiniS. M,Farahani, JolaiF. and Ghodsypour S. H., "Integrated multi-site production-distribution planning in supply chain by hybrid modeling. International Journal of Production Research", Vol.48 (14), Pp:4043-4069, 2010.

[38] Safaei A.S, Moattar Husseini S.M, Farahani R.Z, Jolai .F and Ghodsypour S.H., "Integrated multi-site production-distribution planning in supply chain by hybrid modeling", International Journal of Production Research, Vol.48 (14), Pp:4043-4069,2010.

[39] Taguchi, G. "Introduction to quality engineering. White Plains: Asian Productivity Organization/UNIPUB”, 1986.

[40] Xu J, Kelly J.P., A new network flow-based tabu search heuristic for the vehicle routing problem. Transport Sci, Vol. 30, Pp:379-93, 1996. 